\title{
Evidence for Cardiomyopathy in
}

\section{Familial Diabetes Mellitus}

\author{
Timothy J. Regan, Michael M. Lyons, S. Sultan Ahmed, Gilbert E. Levinson, \\ Henry A. Oldewurtel, Mehmood R. Ahmad, and Bunyad Haider, The \\ Departments of Medicine and Pathology, College of Medicine and Dentistry of \\ New Jersey-New Jersey Medical School, and the Martland Hospital Unit, \\ Newark, New Jersey 07103
}

A B S T RAC T Recent epidemiologic studies have suggested that cardiac disease is common in diabetics and may often have a noncoronary basis. To examine the status of the left ventricle, 17 adult-onset diabetics of familial type without hypertension or obesity underwent hemodynamic study and were compared to 9 controls of similar age.

Of the 17, 12 subjects had no significant occlusive lesions by coronary angiography. From this group eight without heart failure had a modest, but significant, elevation of left ventricular end-diastolic pressure. End-diastolic and stroke volumes were reduced, but ejection fraction and mean rate of fiber shortening were within normal limits. The left ventricular enddiastolic pressure/volume ratio was significantly higher than controls. Afterload increments effected a significant increase of filling pressure compared to normals without a stroke volume response, consistent with a preclinical cardiomyopathy. Four patients with prior heart failure had similar but more extensive abnormalities. None had local dyskinesia by angiography, and lactate production was not observed during pacing-induced tachycardia. Left ventricular biopsy in two patients without ventricular decompensation showed interstitial collagen deposition with relatively normal muscle cells. These findings suggest a myopathic process without ischemia.

Postmortem studies were performed in 11 uncomplicated diabetics. Nine were without significant obstructive disease of the proximal coronary arteries, and the majority succumbed with cardiac failure. On left ventricular sections, none had evident luminal narrowing of the intramural vessels. All nine exhibited periodic acid-Schiff-positive material in the interstitium. Collagen accumulation was present in perivascular loci, between myofibers, or as replacement

Received for publication 30 April 1976 and in revised form 23 May 1977. fibrosis. Multiple samples of left ventricle and septum revealed enhanced triglyceride and cholesterol concentrations, as compared to controls. Thus, a diffuse extravascular abnormality may be a basis for cardiomyopathic features in diabetes.

\section{INTRODUCTION}

A relatively high incidence of cardiac deaths in patients with diabetes mellitus has been attributed to coronary atherosclerosis and its complications (1). However, two recent studies of vessel pathology in diabetics failed to support the assumption that all cardiac deaths were related to this process. In a quantitative study of the extent of surface involvement in the coronary vessels, only a modest increase in the quantity of atherosclerotic disease was present in diabetics compared to age- and sex-matched controls (2). In addition, Ledet observed that intramural vessels commonly exhibited accumulation of glycoprotein but did not show luminal narrowing (3). Thus, the question is raised as to whether a portion of the cardiac diabetic population may have primary myocardial abnormalities as a basis for their symptomatology, independent of ischemia, hypertension, or obesity.

As an initial approach to this problem in a canine model with chronic diabetes, ventricular function and compliance were observed to be abnormal (4), associated with accumulation of periodic acid-Schiff(PAS) positive glycoprotein in the myocardium as well as increments of triglyceride. In humans, a functional abnormality was also found in noncardiac adult diabetics by the systolic time-interval method (5), similar to the preclinical abnormality of ethanolism $(6,7)$.

This report is concerned with an examination of left ventricular function and coronary arteriograms after the development of cardiac symptoms in uncomplicated adult diabetics with a familial history, to determine if the development of symptomatology is de- 
pendent on the presence of myocardial ischemia. A second approach involved morphologic studies at autopsy of diabetics who, except for age and duration of diabetes, had characteristics similar to those in the clinical study.

\section{METHODS}

Patients were selected from the diabetes clinic to investigate symptomatology of chest pain or dyspnea. After obtaining informed consent, cardiac catheterization was performed to evaluate the presence of coronary artery disease and left ventricular dysfunction. All had normal sinus rhythm and were compared hemodynamically with a group of nondiabetic subjects who after diagnostic catheterization were considered to be "hemodynamic normals." In the diabetic subjects diagnosis was established in each before the onset of cardiac symptoms, since glucose intolerance may occur secondary to heart disease (8). None were known to have had pancreatitis. They were generally well controlled without ketosis having been treated by diet, insulin, or oral hypoglycemic agents in a dosage of $0.5-2 \mathrm{~g}$ daily (Table I). Patients were in good clinical status at the time of study with fasting blood sugar ranging from 134 to $213 \mathrm{mg} / 100 \mathrm{mg}$. Most has some degree of retinopathy, and one had neuropathy. None had anemia or uremia, but three evidenced albuminuria. Three with the longest duration of diabetes had manifestations of peripheral vascular disease. Serum cholesterol and triglyceride were within normal limits in the majority according to age and sex criteria (9): six of eight in group A-1 (normal coronary angiograms and no heart failure); three of four in group A-2 (normal coronary angiograms with heart failure); and two of five in group B (significant coronary disease).

Excluded from this phase of the study were patients who had a history or clinical evidence of myocardial infarction, marked obesity, or hypertension. Several diabetic individuals were moderately obese but to an extent no greater than in the controls and not sufficient to be considered as obesediabetic according to a recent classification (10). Neither group contained subjects more than $35 \%$ overweight, the level below which obesity may have little effect on mortality rate when compared to age-matched controls (11). Patients were also excluded if they smoked a pack or more cigarettes per day or had been addicted to ethanol in the past. The latter was usually confirmed by interview of a relative or friend, and was supported by the fact that the patient regularly kept appointments to the diabetes clinic.

Subjects were studied by right and left heart catheterization in the basal, postabsorptive state under mild barbiturate sedation and local procaine analgesia. Catheters were placed in the main pulmonary artery, left ventricular chamber, and aortic root. The left ventricle was entered by retrograde catheterization of the right brachial artery with a $7 \mathrm{~F}$ NIH catheter, $80 \mathrm{~cm}$ long, which was connected directly to a strain gauge via a single three-way stopcock. Catheters of this dimension used for animal studies in this laboratory have been compared with the Millar catheter tip micro-

TABLE I

Clinical Data of Diabetic Patients

\begin{tabular}{|c|c|c|c|c|c|c|c|c|}
\hline \multirow[b]{2}{*}{ Group } & \multirow{2}{*}{$\begin{array}{c}\text { Duration of } \\
\text { diabetes }\end{array}$} & \multirow{2}{*}{$\begin{array}{l}\text { Age, race, } \\
\text { and sex }\end{array}$} & \multirow{2}{*}{$\begin{array}{l}\text { Body wt } \\
\text { (ideal) }\end{array}$} & \multirow{2}{*}{$\begin{array}{l}\text { Treat- } \\
\text { ment* }\end{array}$} & \multirow[b]{2}{*}{ Anginat } & \multicolumn{2}{|c|}{ Heart, presence of } & \multirow[b]{2}{*}{ Fundi } \\
\hline & & & & & & Failure & Enlargement & \\
\hline & $y r$ & & $\%$ & & & & & \\
\hline \multicolumn{9}{|l|}{ A-1 } \\
\hline J. J. & 0.5 & $49 \mathrm{BM}$ & 110 & D & A & - & - & $\mathbf{R}$ \\
\hline C. D. & 0.5 & $61 \mathrm{BM}$ & 116 & $\mathrm{D}$ & A & - & - & $\mathbf{R}$ \\
\hline M. D. & 0.5 & $38 \mathrm{BF}$ & 111 & D & $\mathrm{C}$ & - & + & $\mathbf{R}$ \\
\hline H. W. & 1 & $33 \mathrm{BM}$ & 97 & I & A & - & - & - \\
\hline V. D. & 4 & $49 \mathrm{BF}$ & 121 & $\mathrm{O}$ & $\mathrm{C}$ & - & - & $\mathbf{R}$ \\
\hline E. B. & 5 & $54 \mathrm{BF}$ & 119 & $\mathrm{O}$ & A & - & - & $\mathbf{M}$ \\
\hline V. J. & 6 & $59 \mathrm{BF}$ & 105 & $\mathrm{D}$ & C & - & - & $\mathbf{M}$ \\
\hline C. L. & 7 & $51 \mathrm{BM}$ & 100 & O & A & - & - & $\mathbf{M}$ \\
\hline \multicolumn{9}{|l|}{ A-2 } \\
\hline M. A. & 4 & $57 \mathrm{WF}$ & 102 & D & $\mathrm{C}$ & + & - & $\mathbf{R}$ \\
\hline T. G. & 18 & $42 \mathrm{WF}$ & 100 & I & - & + & + & $\mathbf{M}$ \\
\hline A. $\mathbf{R}$. & 20 & $45 \mathrm{BF}$ & 108 & I & - & + & + & $\mathrm{H}$ \\
\hline D. C. & 21 & $54 \mathrm{BF}$ & 103 & I & A & + & + & $\mathbf{H}$ \\
\hline \multicolumn{9}{|l|}{ B } \\
\hline E. T. & 2 & $43 \mathrm{BM}$ & 115 & $\mathrm{D}$ & - & + & + & - \\
\hline P. H. & 3 & $39 \mathrm{BM}$ & 133 & D & C & - & + & $\mathbf{R}$ \\
\hline E. H. & 8 & $44 \mathrm{BM}$ & 124 & I & C & - & - & $\mathbf{M}$ \\
\hline D. P. & 10 & $56 \mathrm{WF}$ & 87 & $\mathrm{O}$ & C & + & + & $\mathrm{Ct}$ \\
\hline H. D. & 26 & $54 \mathrm{BM}$ & 95 & I & C & + & + & $\mathbf{M}$ \\
\hline
\end{tabular}

* I, insulin; D, dietary, $\mathrm{O}$, oral hypoglycemia agents.

$\downarrow \mathrm{A}$, atypical angina; $\mathrm{C}$, classical angina.

$\S R$, retinal venous dilatation; $M$, microaneurysms; $H$, hemorrhages and (or) exudates; $\mathrm{Ct}$, cataract. 
manometer and have given equivalent systolic and enddiastolic pressures, in accord with a prior study (12). A polyethylene catheter (ID $1.13 \mathrm{~mm}$ and $70 \mathrm{~cm}$ long) was introduced through the left brachial artery by the Seldinger technique and advanced to the aortic root $1-2 \mathrm{~cm}$ above the valve. Catheters were flushed intermittently with degassed saline. Pressures were recorded on an oscilloscopic recorder simultaneously from the left ventricle and aorta using Statham strain gauges (P23Gb, Statham Instruments, Inc., Oxnard, Calif.) for the left ventricular pulse and a zero reference point taken at the mid-chest with the patient supine.

Ventricular diastolic pressure was recorded at a sensitivity where $1 \mathrm{~mm} \mathrm{Hg}$ equaled $5 \mathrm{~mm}$ on the tracing at a paper speed of $100 \mathrm{~mm} / \mathrm{s}$. The frequency response of the system was linear from 0 to 30 cycles/s. End-diastolic pressures were measured over at least two respiratory cycles and then averaged.

Cardiac output was measured from indocyanine green dilution curves sampled from the aortic root after pulmonary artery injection. Three successive curves were averaged to calculate the forward flow. Stroke volume, stroke work, as well as end-diastolic volume calculated as the ratio of mean stroke volume to mean ejection fraction, were then obtained as previously reported (13). The left ventricular ejection fraction was measured by indicator dilution using indocyanine green dye introduced into the left ventricle at the level of the inflow tract. The injection and sampling characteristics of this system have been previously described (13). Briefly, the dye was introduced by sudden injection, and blood was sampled in the aortic root at $2 \mathrm{ml} / \mathrm{s}$ through a Gilford densitometer (Gilford Instrument Co., Oberlin, Ohio) by means of a Harvard pump (Harvard Apparatus Co., Inc., Millis, Mass.). Sampling system dead space was $<2.1 \mathrm{ml}$, a volume sufficiently small to clear the system at heart rates of $<120 / \mathrm{min}$ (present in the study patients), given the rapid sampling rate. Under these conditions in a hydraulic model, distortion of the indicator dilution curves was not seen. Left ventricular ejection fraction by this technique has shown good reproducibility in this model under nearly ideal conditions of mixing and sampling with a mean coefficient of variation of $3 \%(13)$.

Mixing has been a problem for the in vivo measurement of volume in the right ventricle, presumably due to inflow patterns which promote nonmixing (14). To determine if satisfactory mixing occurs in the left ventricle of the normal intact anesthetized dog, we have compared sequential ejection fractions after fluoroscopic placement of a GoodaleLubin catheter in different locations of the left ventricle for injection of $5 \mathrm{ml}$ of dye in normal saline. Each ventricular location was compared with the left atrial injection site, which is assumed to provide complete mixing of dye with ventricular chamber blood, inasmuch as identical indicator dilution downstroke slopes have been obtained after injections into either chamber of an atrioventricular model (15). In addition, a previous study comparing left ventricular end-diastolic volume measurements during injection of a thermal indicator into the left atrium or ventricle of the intact dog, revealed a correlation coefficient of 0.98 between these two injection sites (16). To assess this point in regard to indocyanine green, serial comparisons were made in which heart rate and aortic pressure were comparable in the intact anesthetized dog. Four left atrial injections were made via a catheter followed immediately by injections at the apex of the ventricle for four determinations, with a correlation coefficient of 0.97 in 12 comparisons (4). The atrial injections were then repeated, and the catheter was immediately placed in the midventricle at the level of the inflow tract; the correlation coefficient was 0.94 for 12 comparisons. After a third atrial run, dye was injected into the upper third of the ventricular chamber in the outflow tract, yielding a relatively low correlation.

These data indicate that the requirement for adequate mixing of dye with blood in the ventricle is met by injections at the level of the apex and inflow tract, the site used in these studies in man. Reproducibility in normal humans has been good with a mean coefficient of variation of $5.1 \%$ (13). It appears likely that in subjects with normal chamber size, as in our group A-1 patients or in patients with mild-to-moderate enlargement, adequate mixing of dye occurs.

With the angiographic technique, rapid sequential measurements are not feasible as with green dye, because sustained depression of ventricular function may be produced in the abnormal heart (17). It is known that the ejection fraction in man differs by the two techniques, the angiographic method yielding a value $\cong 14 \%$ higher when compared at similar levels of heart rate and aortic pressure (18). This is thought to be due to a higher rate of ejection as a result of the large bolus of contrast material injected into the left ventricular chamber. Thus, in animals with endocardial radiopaque markers for comparison, a $1-\mathrm{ml} / \mathrm{kg}$ injection of angiographic dye elicited a $12 \%$ ejection fraction increment between the second and fourth beat, as calculated from the endocardial markers, and persisted at a higher level for many beats (19). Left ventricular systolic and diastolic pressures and the first derivative of ventricular pressure were increased by 15,22 , and $17 \%$, respectively. After a $5-\mathrm{ml}$ injection of indocyanine green into the left ventricular chamber in man, we have observed no significant effect on these pressures during transcription of the dye curve, so that the injection artifact appears to be negligible with the indicator dilution method. Despite a systematic difference between the two techniques, there is a good correlation of the ejection fraction derived from the indicator dilution and angiographic techniques, with a correlation coefficient of 0.824 (18).

In terms of end-diastolic volume, the angiographic technique has yielded systematically lower values than the indicator dilution method, averaging $13 \%$ lower in the Hugenholtz study with a correlation coefficient of 0.96 (18). While an absolute test of accuracy in vivo is not available, two additional studies comparing the indicator dilution technique with independent methods have shown good agreement $(20$, 21 ). The former (20) represents a revision of a previous conclusion that the indicator dilution technique differed substantially from angiographic data $(22)$. For the above reasons and the fact that valid angiograms were obtained in a minority of normals, the indicator dilution method was the primary technique used in this study.

In addition to ejection fraction, the mean rate of fiber shortening was evaluated by dividing the difference between the calculated end-diastolic and systolic circumferences by the product of the systolic ejection period and end-diastolic circumference. The dilution curves, pressures, electrocardiograms (ECG) were recorded on an Electronics for Medicine, Inc., (White Plains, N.Y.) DR-8 recorder. In selected patients, ventricular function was also assessed during afterload increments with angiotensin $(6,22)$.

Selective coronary arteriography was performed by the technique of Sones and Shirley, using multiple projections to minimize vessel overlap (23). Additional views were obtained as deemed necessary after review of the videotape recordings. Angiographic data were analyzed by two independent observers. When the interpretations were not in agreement, the arteriograms were reviewed jointly for a compromise interpretation. Coronary arterial disease was graded according to previously published criteria (24). Before 
coronary arteriography, ventriculograms were obtained in the $30^{\circ}$ right anterior oblique projection to measure left ventricular ejection fraction and end-diastolic volume (25) as well as anterior wall thickness at the middle one-third of the ventricle (26). Evaluation for wall motion abnormality was performed according to the method described by Herman et al. (27).

To assess the potential presence of myocardial ischemia, a pacing catheter was placed in the right atrium, the rate was accelerated to between 130 and 145 for $6 \mathrm{~min}$, and the patients were studied during one-to-one conduction. A coronary sinus catheter tip was positioned half-way between the ostium and the border of the cardiac silhouette and was frequently checked to verify its position. In the control and pacing states, serial paired samples were taken from the aorta and coronary vein for substrate analyses, and the whole blood was immediately deproteinized with $6 \%$ perchloric acid. The clear supernate was kept chilled, stored frozen, and analyzed within 6 days, a period in which the substrates in the perchloric extracts have been found to remain stable. Lactic and pyruvic acids were determined in duplicate enzymatically using fluorometry $(28,29)$ to quantitate the appearance or disappearance of reduced NAD. The analyses were performed simultaneously with a two-channel AutoAnalyzer system (Technicon Instruments Corp., Tarrytown, N.Y.) equipped with two fluorometers. Internal standards gave recovery rates of $95-100 \%$. The reproducibility of duplicate blood samples was within $3 \%$ of each other for lactate and $5 \%$ for pyruvate. The significance of differences in substrate and hemodynamic data was tested by Student's unpaired $t$ test.

The second part of the study involved autopsies of diabetics who had a previous diagnostic work-up or a sufficiently long hospital stay to permit diagnostic study. These patients had similar characteristics as the first group, but were older and known to be diabetic for a somewhat longer average duration. Autopsies were performed within $18 \mathrm{~h}$ of death during which time the body was kept at $5^{\circ} \mathrm{C}$. The left main coronary artery and its epicardial branches were transsected in situ at 4-mm intervals to determine luminal narrowing, estimated visually as the percentage reduction of the crosssectional area when compared to the normal lumen. Each heart was cut in $1-\mathrm{cm}$ slices for visual examination. Histochemical examinations were performed on left ventricular specimens, $10 \times 2 \mathrm{~mm}$ and $5 \mu \mathrm{m}$ in thickness, taken from the free wall at the apex and halfway to the base as well as the anterior and posterior segments of septum. These included hematoxylin-eosin, trichrome, Alician blue, PAS after diastase treatment, and Congo red with polarized light $(30,31)$. Comparative studies were also performed in five nondiabetics of similar age range without known cardiovascular disease. After the histological sections were prepared, the final interpretations and estimates of the degree of positivity of the PAS and trichrome stains were evaluated by the pathologist without knowledge of the diagnosis. Slides from the nondiabetic controls and diabetics were intermixed as unknowns for blind grading. The two groups were compared by the Mann-Whitney test for two independent samples, using the actual ranks of the different observations (32).

The light microscopy studies were supplemented by a limited electron microscopic study. As a feasible approach to examining myocardial ultrastructure, biopsies were obtained in diabetics during open heart surgery for valve replacement using a Vim-Silverman-type needle. Samples were taken from the free wall of the left ventricle, $\cong 1 \mathrm{~cm}$ above the apex at the anticipated site of venting; these were 6-8 $\mathrm{mm}$ long and 1-2 $\mathrm{mm}$ in diameter. This was limited to patients with pure mitral stenosis because the left ventricle does not enlarge and frequently exhibits normal function in adults with this disease $(33,34)$. These additional diabetic patients, 49-56 yr of age, were without complications and were compared with a 44-yr-old nondiabetic with mitral stenosis without evidence of left ventricular dysfunction by angiographic or hemodynamic measurements. For electron microscopy, samples were immediately diced and fixed in cold glutaraldehyde buffered with lead and uranyl acetate and imbedded in Epon.

To assess whether the lipid composition of the ventricle was altered in a manner similar to the diabetic animal model (4), 1-g samples of grossly normal ventricle were taken from the same sites as the tissue for morphological examination. After trimming, these were analyzed for triglyceride (35), phospholipid (36), and cholesterol (37).

\section{RESULTS}

17 patients had coronary angiograms. There was no significant obstructive disease of the coronary vessels in 12 patients, as judged by two independent viewers. This included two subjects who had single vessel involvement with narrowing of lumen diameter $<30 \%$. Ventriculograms showed no evidence of regional contractile deficits, mitral regurgitation, or floppy valve. These were designated as group $\mathrm{A}$, with a mean age of $49 \pm 3.5 \mathrm{yr}$; the clinical data is summarized in Table $I$.

Diabetic group A-1 consisted of eight of these subjects who had no clinical evidence of heart failure. Heart size appeared normal by conventional cardiac series, angiographic criteria, and ECG, except for one who had mild left ventricular enlargement. This group exhibited a significant reduction of stroke volume index and elevation of end-diastolic pressure at rest (Table III), as compared to controls of similar age range (Table II). Inasmuch as end-diastolic volume was significantly less than in controls, the reduced stroke volume appeared to be secondary to abnormal filling of the ventricle. Using the ratio of end-diastolic filling pressure to volume as an indicator of end-diastolic wall stiffness, a significant increment was present in the diabetic group (Table III). Ejection fraction by the indicator-dilution technique did not differ significantly from controls. The mean rate of fiber shortening also showed no significant difference at $1.76 \pm 0.29$ circumference/s in normals and $1.48 \pm 0.19$ circumference/s in this group of diabetics.

In five patients of group A-1, the status of the ventricle was further assessed during infusion of angiotensin at a rate which was adjusted to raise aortic diastolic pressure between $15-18 \mathrm{~mm} \mathrm{Hg}$. The dose of hormone averaged $1.5 \mu \mathrm{g} / \mathrm{kg}$ per min over a 15 -min period. Although the response in normals was associated with a significant stroke volume increment and a small rise of end-diastolic pressure (6), the diabetics demonstrated a significant rise of filling pressure compared to controls $(P<0.02)$, without a significant increment of stroke volume (Table IV). These hemo- 
TABLE II

Left Ventricular Hemodynamics in Controls

\begin{tabular}{|c|c|c|c|c|c|c|c|c|}
\hline \multirow[b]{2}{*}{$\begin{array}{l}\text { Age, race, } \\
\text { and sex }\end{array}$} & \multirow[b]{2}{*}{$\begin{array}{l}\text { Body wt } \\
\text { (ideal) }\end{array}$} & \multirow[b]{2}{*}{$\begin{array}{c}\text { Heart } \\
\text { rate }\end{array}$} & \multirow[b]{2}{*}{$\begin{array}{c}\text { Aortic } \\
\text { pressure }\end{array}$} & \multicolumn{2}{|c|}{$\begin{array}{l}\text { Left ventricular } \\
\text { end-diastolic }\end{array}$} & \multirow[b]{2}{*}{ EDP/EDV* } & \multirow{2}{*}{$\begin{array}{c}\text { Stroke } \\
\text { volume } \\
\text { index }\end{array}$} & \multirow[b]{2}{*}{$\begin{array}{l}\text { Ejection } \\
\text { fraction }\end{array}$} \\
\hline & & & & Pressure & $\begin{array}{l}\text { Volume } \\
\text { index }\end{array}$ & & & \\
\hline & $\%$ & & $m m \mathrm{Hg}$ & $m m \mathrm{Hg}$ & $m l$ & & $m l$ & $\%$ \\
\hline $37 \mathrm{BM}$ & 103 & 81 & $118 / 83$ & 8 & 100.5 & 0.040 & 45.1 & 0.45 \\
\hline $41 \mathrm{WF}$ & 128 & 80 & $119 / 81$ & 10 & 90.6 & 0.055 & 48.9 & 0.54 \\
\hline $38 \mathrm{BF}$ & 96 & 72 & $110 / 60$ & 11 & 82.4 & 0.075 & 46.6 & 0.57 \\
\hline $45 \mathrm{BM}$ & 115 & 60 & $104 / 62$ & 10 & 79.9 & 0.076 & 45.1 & 0.56 \\
\hline $49 \mathrm{WF}$ & 109 & 63 & $100 / 62$ & 8 & 81.8 & 0.065 & 49.4 & 0.60 \\
\hline $53 \mathrm{BM}$ & 131 & 90 & $119 / 86$ & 5 & 74.9 & 0.049 & 42.8 & 0.56 \\
\hline $44 \mathrm{BF}$ & 104 & 85 & $129 / 88$ & 8 & 61.0 & 0.069 & 32.8 & 0.52 \\
\hline $42 \mathrm{BF}$ & 122 & 63 & $125 / 81$ & 7 & 109.1 & 0.046 & 55.0 & 0.51 \\
\hline $41 \mathrm{BM}$ & 107 & 85 & $115 / 64$ & 9 & 68.8 & 0.088 & 32.2 & 0.47 \\
\hline Mean 44.4 & 112.8 & 75 & $115 / 74$ & 8.4 & 83.2 & 0.062 & 44.2 & 0.53 \\
\hline SE $\quad 1.87$ & 4.0 & 3.7 & $3.1 / 3.9$ & 0.60 & 5.0 & 0.005 & 2.5 & 0.01 \\
\hline
\end{tabular}

* EDP, end-diastolic pressure; EDV, end-diastolic volume.

dynamic data are consistent with the response of a cardiac medications were discontinued. They were preclinical cardiomyopathy.

Four diabetics (group A-2) had episodes of cardiac similar in age to group A-1 but tended to have a longer duration of diabetes and lower body weight, failure for 6-15 mo and were studied at least $48 \mathrm{~h}$ after as well as ECG evidence of hypertrophy and minor

TABLE III

Ventricular Hemodynamics in Diabetics with Normal Coronary Angiograms

\begin{tabular}{|c|c|c|c|c|c|c|c|}
\hline \multirow[b]{2}{*}{ Group } & \multirow[b]{2}{*}{$\begin{array}{c}\text { Heart } \\
\text { rate }\end{array}$} & \multirow[b]{2}{*}{$\begin{array}{c}\text { Aortic } \\
\text { pressure }\end{array}$} & \multicolumn{2}{|c|}{$\begin{array}{l}\text { Left ventricular } \\
\text { end-diastolic }\end{array}$} & \multirow[b]{2}{*}{ EDP/EDV } & \multirow{2}{*}{$\begin{array}{l}\text { Stroke } \\
\text { volume } \\
\text { index }\end{array}$} & \multirow[b]{2}{*}{$\begin{array}{l}\text { Ejection } \\
\text { fraction }\end{array}$} \\
\hline & & & Pressure & $\begin{array}{l}\text { Volume } \\
\text { index }\end{array}$ & & & \\
\hline & & $m m \mathrm{Hg}$ & $\mathrm{mm} \mathrm{Hg}$ & $m l$ & & $m l$ & $\%$ \\
\hline \multicolumn{8}{|l|}{ A-1 } \\
\hline J. J. & 70 & $105 / 75$ & 9 & 58 & 0.090 & 26.2 & 0.44 \\
\hline C. D. & 64 & $127 / 78$ & 15 & 69 & 0.113 & 38.1 & 0.55 \\
\hline M. D. & 79 & $138 / 84$ & 12 & & & 34.0 & \\
\hline H. W. & 55 & $121 / 73$ & 13 & 79 & 0.092 & 38.6 & 0.49 \\
\hline V. D. & 65 & $141 / 76$ & 13 & & & 32.1 & \\
\hline E. B. & 85 & $130 / 80$ & 10 & 59 & 0.080 & 30.7 & 0.53 \\
\hline V. J. & 90 & $110 / 75$ & 11 & 59 & 0.098 & 24.3 & 0.41 \\
\hline C. L. & 75 & $130 / 84$ & 9 & 51 & 0.106 & 25.0 & 0.49 \\
\hline Mean & 72.9 & $125 / 78$ & 11.5 & 62.5 & 0.097 & 31.1 & 0.49 \\
\hline SE & 4.1 & $4.5 / 1.5$ & 0.75 & 4.0 & 0.004 & 2.0 & 0.02 \\
\hline$P \downarrow$ & NS & NS & $<0.01$ & $<0.01$ & $<0.005$ & $<0.001$ & NS \\
\hline \multicolumn{8}{|l|}{ A-2 } \\
\hline M. A. & 83 & $102 / 68$ & 10 & & & 22 & \\
\hline T. G. & 86 & $112 / 65$ & 11 & & & 21 & \\
\hline A. $\mathbf{R}$. & 87 & $140 / 80$ & 15 & 68 & 0.132 & 27 & 0.40 \\
\hline D. C. & 81 & $145 / 78$ & 16 & 88 & 0.110 & 27 & 0.30 \\
\hline Mean & 84.3 & $125 / 73$ & 13.0 & 78 & 0.121 & 24.3 & 0.35 \\
\hline SE & 1.4 & $10.5 / 3.7$ & 1.5 & & & 1.6 & 0.05 \\
\hline$P \ddagger$ & NS & NS & $<0.02$ & & & $<0.001$ & $<0.005$ \\
\hline
\end{tabular}

* EDP, end-diastolic pressure; EDV, end-diastolic volume.

† Nonpaired $t$ test vs. controls. 
TABLE IV

Hemodynamic Response to Angiotensin*

\begin{tabular}{|c|c|c|c|c|c|}
\hline & \multirow{2}{*}{$\begin{array}{l}\text { Heart } \\
\text { rate }\end{array}$} & \multicolumn{2}{|c|}{ Aortic pressure } & \multirow{2}{*}{$\begin{array}{c}\text { Stroke } \\
\text { volume } \\
\text { index }\end{array}$} & \multirow{2}{*}{$\begin{array}{c}\text { Left ventricular } \\
\text { end-diastolic } \\
\text { pressure }\end{array}$} \\
\hline & & Mean & Diastolic & & \\
\hline & & \multicolumn{2}{|c|}{$m m \mathbf{H g}$} & $\mathrm{ml} / \mathrm{m}^{2}$ & $m m \mathbf{H g}$ \\
\hline \\
\hline$(n=8) \mathrm{C}$ & $81 \pm 3.7$ & $101 \pm 5$ & $83 \pm 3.9$ & $38.4 \pm 2.9$ & $6.7 \pm 0.6$ \\
\hline E & $75 \pm 4.9$ & $130 \pm 7$ & $104 \pm 4.1$ & $45.1 \pm 2.8$ & $9.5 \pm 0.5$ \\
\hline \multicolumn{6}{|l|}{$\begin{array}{l}\text { Diabetics } \\
\text { group A-1 }\end{array}$} \\
\hline$(n=5) \mathrm{C}$ & $74 \pm 6.6$ & $99 \pm 6$ & $76 \pm 4.8$ & $25.8 \pm 2.0$ & $10.2 \pm 1.1 \ddagger$ \\
\hline $\mathbf{E}$ & $70 \pm 5.1$ & $127 \pm 5$ & $95 \pm 3.7$ & $27.3 \pm 2.6$ & $16.1 \pm 0.9$ \\
\hline
\end{tabular}

$\mathrm{C}$ refers to data at rest before angiotensin infusion. $\mathrm{E}$ refers to data during angiotensin infusion.

* Control data previously presented (6).

I Nonpaired $t$ test was $P<0.02$.

repolarization changes. Stroke volume was reduced still more, associated with a higher end-diastolic pressure and an elevated ratio of end-diastolic pressure to volume (Table III). Diffuse hypokinesis was detected in three of four subjects by ventriculogram.

Ventricular ejection fractions and volumes obtained by the indicator dilution studies were compared with those derived by left ventriculography in 10 of 11 diabetics from the three patient groups, excluding one in whom ectopic beats invalidated the angiogram. The mean value by indicator was $0.419 \pm 0.32 \%$ compared to $0.545 \pm 0.03$ by angiography, with a correlation coefficient of 0.79 . The angiographic value is lower than that in our normals of $0.66 \pm 0.05 \%$. End-diastolic volume by the two techniques gave a correlation coefficient of 0.88 . In the pooled diabetics, the enddiastolic volume index by the indicator method was $68.4 \pm 4.3 \mathrm{ml}$ vs. $61.6 \pm 3.4$ with angiography. Thus, in comparing the diabetic patients of group A-1 with controls, there was a real difference from controls using the same technique in both groups. This malfunction was confirmed by afterload increments.

Since ischemia on a microvascular basis could not be excluded in group A patients, atrial pacing to a rate of 140-145 per minute was induced to determine whether lactate production could be evoked during this stress (Fig. 1). Arterial concentrations of lactate and pyruvate did not change, and the arterial-coronary sinus concentrations of the latter substrate were not significantly altered during the tachycardia in any of the three groups In none of the six diabetics without coronary disease from group A (two from the decompensated subgroup), was there a rise in coronary venous lactate concentrations, a decrease in the arterial-coronary sinus differences, or a significant decline in the coefficient of extraction of lactate as calculated from lactate arterial - venous/arterial concentrations. The latter is clearly above the level seen in diabetic patients with significant coronary angiographic abnormalities (group B), suggesting that the abnormality of myocardial function in group A was not related to ischemia. ECG leads II and $V_{5}$ revealed no significant ST depression during pacing in normals of group $\mathrm{A}$; in three group $\mathrm{B}$ subjects, ST depression was $1 \mathrm{~mm}$ and was associated with anginal pain.

Group B, with an average age of $47 \pm 3.3 \mathrm{yr}$, consisted of diabetic patients who had greater than $50 \%$ reduction of luminal diameter in at least one major coronary artery. In addition to hypertrophy, one had incomplete right bundle branch block and one an anterior hemiblock. Diffuse hypokinesis or local dyskinesia was present in each of the five and mitral regurgitation was observed in one patient (Table V). While stroke volume was reduced and end-diastolic pressure was higher in this group than in group A-1, these resting parameters did not differ from group A-2.

A more advanced stage of diabetes was evaluated at postmortem in 13 diabetic subjects with ages ranging from 43 to $65 \mathrm{yr}$ and fasting blood sugar from 146 to $262 \mathrm{mg} / 100 \mathrm{mg}$. The known duration of diabetes varied from 5 to $28 \mathrm{yr}$. There were nine without significant luminal narrowing of the extramural coronary vessels (Group 1), although fatty streaks or relatively flat, uncomplicated plaques were present in the majority. There was no evidence of diastolic hypertension or marked obesity in the subjects of group 1 , and the serum cholesterol and triglyceride were within the normal range in six of the eight with data available. Patients with significant coronary artery disease were classed as group 2 (Table VI). Six of the nine in group 1 had heart failure in the terminal episode; the remainder had septicemia, renal failure, and stroke. Pulmonary emboli were associated in one-third of the group. Examination of the kidneys revealed a diffuse increase of PAS-positive material in the glomerular mesangium in six patients and nodular glomerulosclerosis in three. None had evidence of hepatic cirrhosis.

Heart weight in group 1 ranged from 300 to 550 $\mathrm{g}$, and three of the nine had gross scar approximating $1 \mathrm{~cm}^{2}$ in the free wall of the left ventricle. No mural thrombi or systemic emboli were found. In examining the status of the intramural vessels, 15 arteries were viewed per tissue section. In four of the nine cases the wall of the smaller intramural vessels was thickened, usually to a mild extent. Not all vessels in these four patients were involved and in none was there unequivocal narrowing. Consequently, there was no clear evidence that either large or small coronary vessel occlusive disease contributed to the myocardial pathology in this group of patients.

Morphological examination was performed on tissue samples as unknowns from areas of muscle that were grossly normal in appearance. There was no evidence of inflammatory cell infiltration but significant ac- 

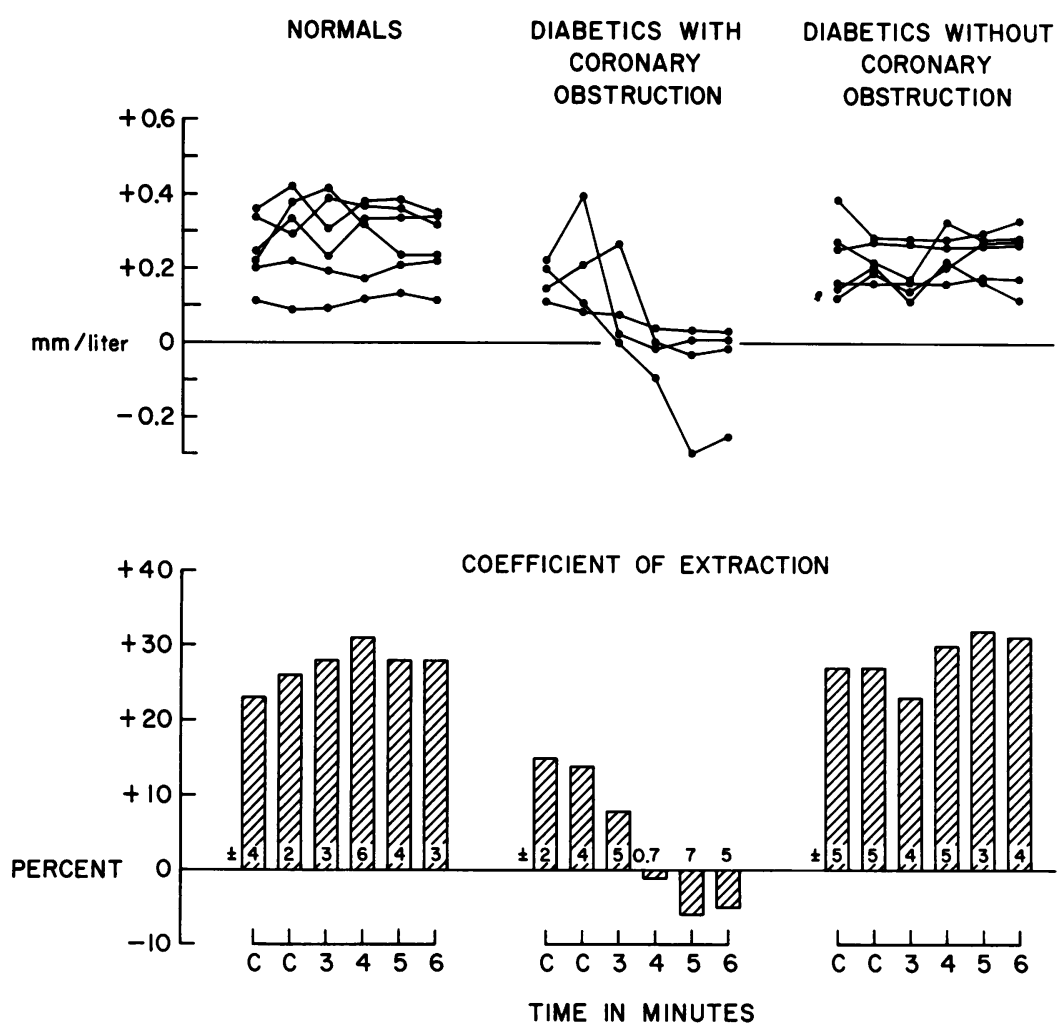

FIGURE 1 The top panel represents the arterial-coronary sinus differences of lactate before (C) and during pacing-induced tachycardia. The bottom panel illustrates the mean coefficients of lactate extraction and standard errors, obtained from the A-V difference divided by arterial concentration.

cumulation of PAS-positive, diastase-resistant material was observed in the interstitium between muscle fibers (Table VI). Controls had no more than a trace, classed as $0-1+($ Fig. $2 a$ ). In diabetics the accumulation of PAS material in a focal form was graded at 2+; when scattered diffusely through the muscle sample, the tissue was graded as $3+$ (Fig. $2 b)$. On statistical analysis using the Mann-Whitney test, the diabetics were significantly different from controls $(P<0.002)$. None of the patients were positive for Congo red under

TABLE V

Ventricular Hemodynamics in Diabetics with Abnormal Coronary Angiograms

\begin{tabular}{|c|c|c|c|c|c|c|c|}
\hline \multirow[b]{2}{*}{ Group B } & \multirow[b]{2}{*}{$\begin{array}{l}\text { Heart } \\
\text { rate }\end{array}$} & \multirow[b]{2}{*}{$\begin{array}{c}\text { Aortic } \\
\text { pressure }\end{array}$} & \multicolumn{2}{|c|}{$\begin{array}{l}\text { Left ventricular } \\
\text { end-diastolic }\end{array}$} & \multirow[b]{2}{*}{ EDP/EDV } & \multirow{2}{*}{$\begin{array}{c}\text { Stroke } \\
\text { volume } \\
\text { index }\end{array}$} & \multirow[b]{2}{*}{$\begin{array}{l}\text { Ejection } \\
\text { fraction }\end{array}$} \\
\hline & & & Pressure & $\begin{array}{l}\text { Volume } \\
\text { index }\end{array}$ & & & \\
\hline & & $m m \mathbf{H g}$ & $m m \mathrm{Hg}$ & $m l$ & & $m l$ & $\%$ \\
\hline E. T. & 116 & $112 / 80$ & 26 & & & 18.3 & \\
\hline P. H. & 82 & $110 / 70$ & 8 & & & 23.0 & \\
\hline E. H. & 118 & $130 / 92$ & 10 & 62.3 & 0.068 & 16.5 & 0.27 \\
\hline D. P. & 59 & $130 / 78$ & 14 & 78 & 0.122 & 38.0 & 0.48 \\
\hline H. D. & 86 & $116 / 68$ & 8 & 90.7 & 0.053 & 28.4 & 0.31 \\
\hline Mean & 92 & $120 / 78$ & 13.2 & 77 & 0.081 & 24.8 & 0.35 \\
\hline SE & 11.1 & $4.4 / 4.3$ & 3.4 & 8.2 & 0.021 & 3.9 & 0.064 \\
\hline$P \ddagger$ & NS & NS & NS & NS & NS & $<0.005$ & $<0.02$ \\
\hline
\end{tabular}

* EDP, end-diastolic pressure; EDV, end-diastolic volume.

\$ Nonpaired $t$ test vs. controls. 
TABLE VI

Pathology of the Heart in Diabetes

\begin{tabular}{|c|c|c|c|c|c|c|c|c|c|c|c|c|}
\hline & \multirow[b]{3}{*}{$\begin{array}{l}\text { Age, race, } \\
\text { and sex }\end{array}$} & \multirow[b]{3}{*}{ Body wt } & \multirow[b]{3}{*}{ Heart wt } & \multirow[b]{3}{*}{$\begin{array}{l}\text { Arterial } \\
\text { pressure }\end{array}$} & \multicolumn{5}{|c|}{ Coronary arteries } & \multicolumn{2}{|c|}{ Left ventricle } & \multirow[b]{3}{*}{$\begin{array}{c}\text { Terminal } \\
\text { illness }\end{array}$} \\
\hline & & & & & \multirow[b]{2}{*}{ Right } & \multicolumn{3}{|c|}{ Left } & \multirow[b]{2}{*}{$\begin{array}{l}\text { Intramural } \\
\text { thickening }\end{array}$} & & & \\
\hline & & & & & & Main & Ant. desc. & Circ. & & PAS & $\begin{array}{l}\text { Interstitial } \\
\text { fibrosis* }\end{array}$ & \\
\hline & & $k g$ & $g$ & & & & & & & & & \\
\hline \multicolumn{13}{|l|}{ Group 1} \\
\hline J. L. & $62 \mathrm{WM}$ & 00 & 300 & $128 / 82$ & 0 & 0 & $\$$ & 0 & Focal & $3+$ & $2+$ & Renal failure \\
\hline M. R. & $43 \mathrm{BF}$ & 00 & 315 & $100 / 60$ & 0 & 0 & 0 & 0 & None & $3+$ & $3+$ & Heart failure \\
\hline W. E. & $50 \mathrm{BM}$ & 00 & 340 & $128 / 75$ & $\ddagger$ & 0 & 0 & $\neq$ & Focal & $1+$ & $2+$ & Septicemia \\
\hline V. D. & $49 \mathrm{BM}$ & 00 & 440 & $136 / 76$ & 0 & 0 & $<50 \%$ & 0 & None & $3+$ & $4+$ & Heart failure \\
\hline H. B. & $48 \mathrm{BM}$ & 00 & 450 & $150 / 92$ & 0 & 0 & 0 & 0 & None & $3+$ & $3+$ & Heart failure \\
\hline C. $\mathbf{R}$. & $63 \mathrm{BM}$ & 00 & 450 & $170 / 90$ & 0 & 0 & $\neq$ & 0 & None & $2+$ & $4+$ & Heart failure \\
\hline E. S. & $64 \mathrm{BM}$ & 00 & 530 & $125 / 86$ & $\ddagger$ & 0 & 0 & 0 & Focal & $3+$ & $1+$ & Stroke \\
\hline T. G. & $42 \mathrm{WF}$ & 00 & 540 & $120 / 80$ & 0 & 0 & $<40 \%$ & 0 & None & $2+$ & $4+$ & Heart failure \\
\hline W. C. & $65 \mathrm{BM}$ & 00 & 550 & $122 / 86$ & 0 & 0 & $\neq$ & 0 & Focal & $3+$ & $3+$ & Heart failure \\
\hline \multicolumn{13}{|l|}{ Group 2} \\
\hline A. B. & 64 WF & 00 & 430 & $145 / 100$ & $85 \%$ & 0 & $85 \%$ & 0 & None & $2+$ & $3+$ & Acute infarction \\
\hline I. B. & $62 \mathrm{BF}$ & 00 & 560 & $110 / 70$ & $<50 \%$ & 0 & $100 \%$ & $30 \%$ & Focal & $3+$ & $2+$ & Acute infarction \\
\hline
\end{tabular}

* 1 or $2+$ when fibrosis predominantly periarterial; 3 and $4+$ refers to penetration of collagen between myofibers. These represent interpretations of tissue sections from the free wall above the apex and are qualitatively similar to the other sampling sites.

$\$$ Fatty streaks.

polarized light, and there was no accumulation of Alcian blue-positive material in myocardium when compared to controls.

In addition, microscopic fibrosis was present to a variable but enhanced extent in left ventricular muscle of diabetics but not in controls (Fig. 3a). In mildest form this was manifested on trichrome stain as accumulation of collagen around intramural vessels to an extent greater than in controls. This was graded as $1+$ when localized and $2+$ when observed throughout the tissue sections (Table VI). In others, the collagen fibers appeared to penetrate from the periarterial location to lie between muscle bundles in a patchy distribution (Fig. 3b). This was graded as $3+$ when there was minimal or no apparent myofiber loss and $4+$ when fragmentation or degeneration of muscle cells was predominant. Comparison of diabetics and controls indicated a significant difference $(P<0.002)$. In three patients of group 1 without significant coronary occlusive disease, there was gross scar near the apex, $\cong 1 \mathrm{~cm}^{2}$. None of these fibrous changes were observed in control hearts.

The two patients in group 2 had significant occlusive disease of the coronary arteries; in one patient this involved multiple points in two vessels. Both died during an acute infarction. Myocardium that was not involved in the latter process had similar alterations of interstitium as observed in group 1.

To assess cardiac ultrastructure in chronic diabetes, electron microscopy was performed on left ventricular transmural biopsies obtained in two additional diabetics during open heart surgery for mitral stenosis. Multiple sections of the biopsy in the diabetic revealed that the interstitium was relatively prominent and characterized by accumulation of collagen and amorphous material, presumably glycoprotein with apparent extension into the T tubules (Fig. 4). At higher magnification, fibroblasts appeared to be active as judged by chromatin localization at the nuclear periphery and a relative abundance of rough endoplasmic reticulum. Within the cardiac cell there were lipid bodies and some increase in mitochondrial number, with pleomorphism but no swelling or evident distortion of cristae. Myofibrils and intercalated disk appeared to be within normal limits, and there was only occasional dilatation of the sarcoplasmic reticulum. These morphologic abnormalities were absent in the nondiabetic with mitral stenosis.

To evaluate further the cardiomyopathic features in the diabetic, sections of muscle from the group 1, patients were taken at postmortem from the free wall at the apex and base, as well as from the anterior and posterior septum. These were trimmed of gross fat and vascular tissue. Despite some variation, the concentration of triglyceride in the left ventricle and septum was significantly elevated above that of nondiabetic controls without heart disease in the four sampling sites (Fig. 5). The $P$ value for free wall at 
the apex was $<0.05$; for base $<0.01$, for anterior septum $<0.05$, and the posterior septum $<0.05$. Cholesterol concentration was elevated in all sampling sites, which was significant at the apex $(P<0.05)$ as well as the anterior $(P<0.01)$, and posterior septum ( $P$ $<0.05)$. Phospholipid concentrations did not differ significantly from the control group. These lipid alterations are similar to those in the diabetic animal model (4) and, as a diffuse process, is consistent with a cardiomyopathy.

\section{DISCUSSION}

A recent epidemiologic study has suggested that cardiac abnormalities in diabetics frequently occur without the usual risk factors associated with coronary atherosclerosis (38). This is in general agreement with a quantitative description of coronary atherosclerosis in diabetics vs. age- and sex-matched controls in that the intimal surface area involved by fibrous plaques or complicated lesions was only modestly increased in diabetes (2). Our own study indicates that patients with cardiac symptomatology who are diabetic may have considerable malfunction of the ventricle as well as abnormal morphology and composition in the absence of significant large vessel occlusive disease.

Obliterative disease of the small coronary arteries has been thought to be important in the pathogenesis of cardiac disease in diabetes in the form of thickened intramural arteries, with occasional bridging of endothelial cells (39-41). However, such lesions were also observed in nondiabetics without evident effects on cardiac muscle (39). Although these studies did not specify the area of ventricle examined, small vessel disease limited to papillary muscles has been found in over $40 \%$ of an unselected and random sample of hospital necropsies (42). Moreover, in amyloid heart disease (43), as well as endomyocardial fibrosis (44, 45), small vessel involvement appears to be independent of tissue necrosis or fibrosis, presumably because the arterial disease is patchy and sufficiently slow in progression to permit collateral development. The failure to find demonstrable obstructive lesions of intramural vessels in the free wall of the left ventricle in prior studies of diabetics $(3,46,47)$, as well as our own, suggests that small vessel lesions in diabetes may have little or no relation to the cardiac pathology.

Lactate production or a decrease in lactate extraction as well as ischemic ECG changes are regular, although nor uniform, features of the myocardial response to pacing in patients with classic angina associated with coronary artery disease (48). Neither of these responses were observed in the diabetic group without significant coronary occlusive disease, compatible with the response of a majority of nondiabetic patients who have anginal type pain without arterial disease (49). Thus, if abnormalities of small arteries or capillaries were present in the group A diabetics with altered ventricular function, these were apparently insufficient to restrict myocardial perfusion. However, one cannot exclude the potential for an occlusive process that is extensive and rapidly developing, so as to effect ischemia in some diabetics.

A preclinical abnormality of left ventricular function has been previously reported in asymptomatic diabetics with normal heart size (5). The symptomatic patients of group A-1 were without heart failure but exhibited a significant change in diastolic parameters at rest and during afterload increments. The reduced stroke volume was presumably related to diminished filling of the ventricle, since ejection phase indices were not significantly reduced. Whether the reduction of end-diastolic and stroke volume in Group A-1 patients is related to a nonspecific factor, such as diminished physical activity due to angina, is considered unlikely. Patients with angina attributable to coronary disease, who do not have elevated filling pressures at rest and with heart rate in the normal range, have been shown to have a normal left ventricular end-diastolic volume (50); those with end-diastolic pressure elevation usually have enhanced end-diastolic volume (51). At rest, subjects with normal filling pressures have stroke index (48), or stroke work (52) levels which are not significantly different from controls. Conversely, normal subjects confined to bed for 5 days to 4 wk do not have a significant change of heart rate or stroke volume at rest (53-55), despite a decrease in total heart volume (54). It is noteworthy that our group A-1 patients with only sporadic appearance of anginal symptoms, were not subject to continuous bed rest and were similar to the nondiabetic hemodynamic controls in terms of ad lib. ambulation during a hospital stay of 1-3 days before study. Thus, the reduction of stroke volume and enddiastolic volume at rest associated with elevated filling pressure, do not appear attributable to physical inactivity.

Since group A-1 was without heart failure or demonstrable cardiac enlargement with one exception, myocardial wall thickening, if present, was apparently minimal and insufficient to affect indices of wall stiffness (56). Thus, the change in muscle function suggestive of enhanced wall stiffness may be related to altered composition in the form of interstitial glycoprotein and collagen accumulation observed in the morphologic studies. Extracellular structures are major determinants of muscle elasticity (57), and the observations in these diabetics are analogous to the amyloid heart where deposits between cardiac muscle cells enhance wall stiffness (58). In addition, in a diabetic animal model in which myofiber cell structure was

Cardiomyopathy in Diabetes 

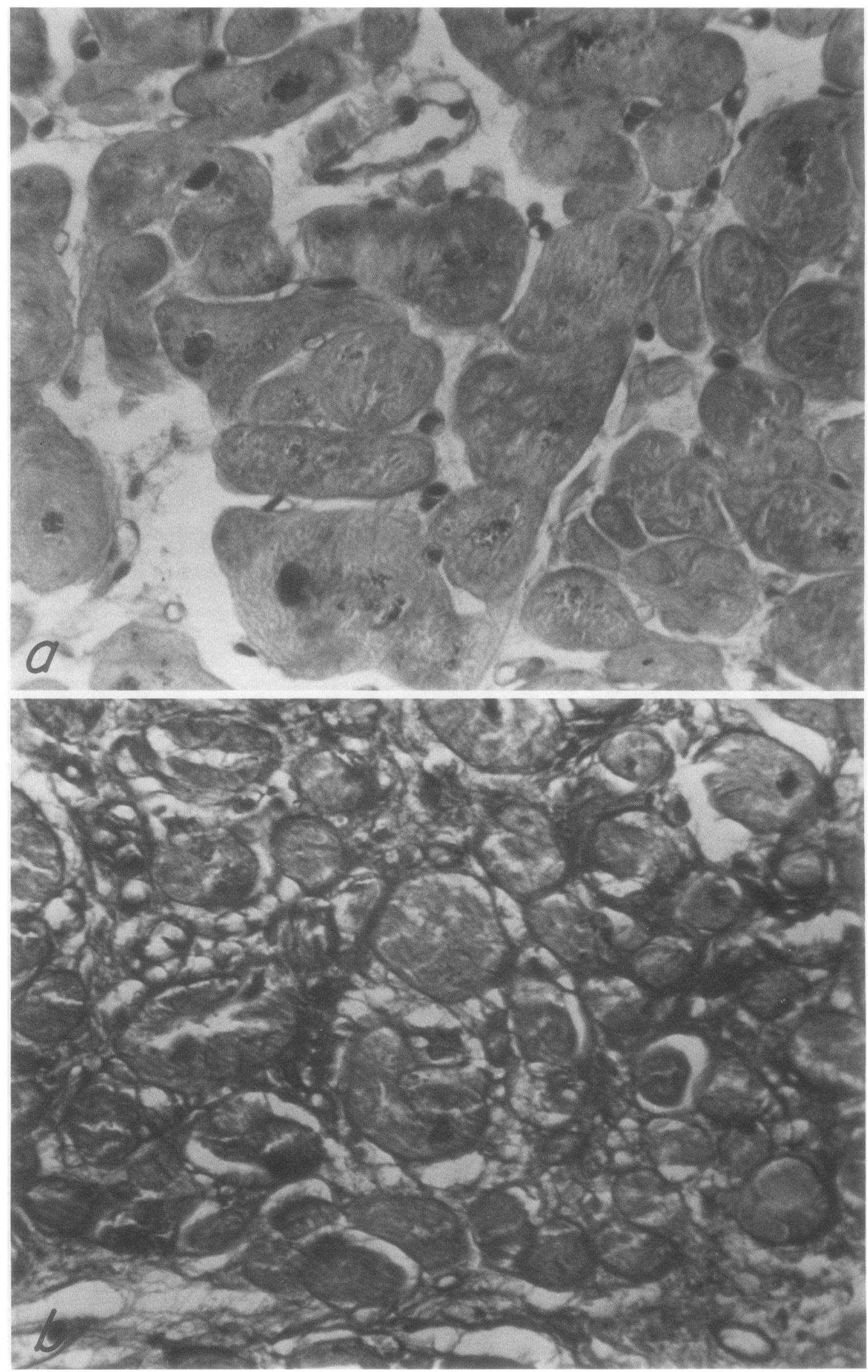

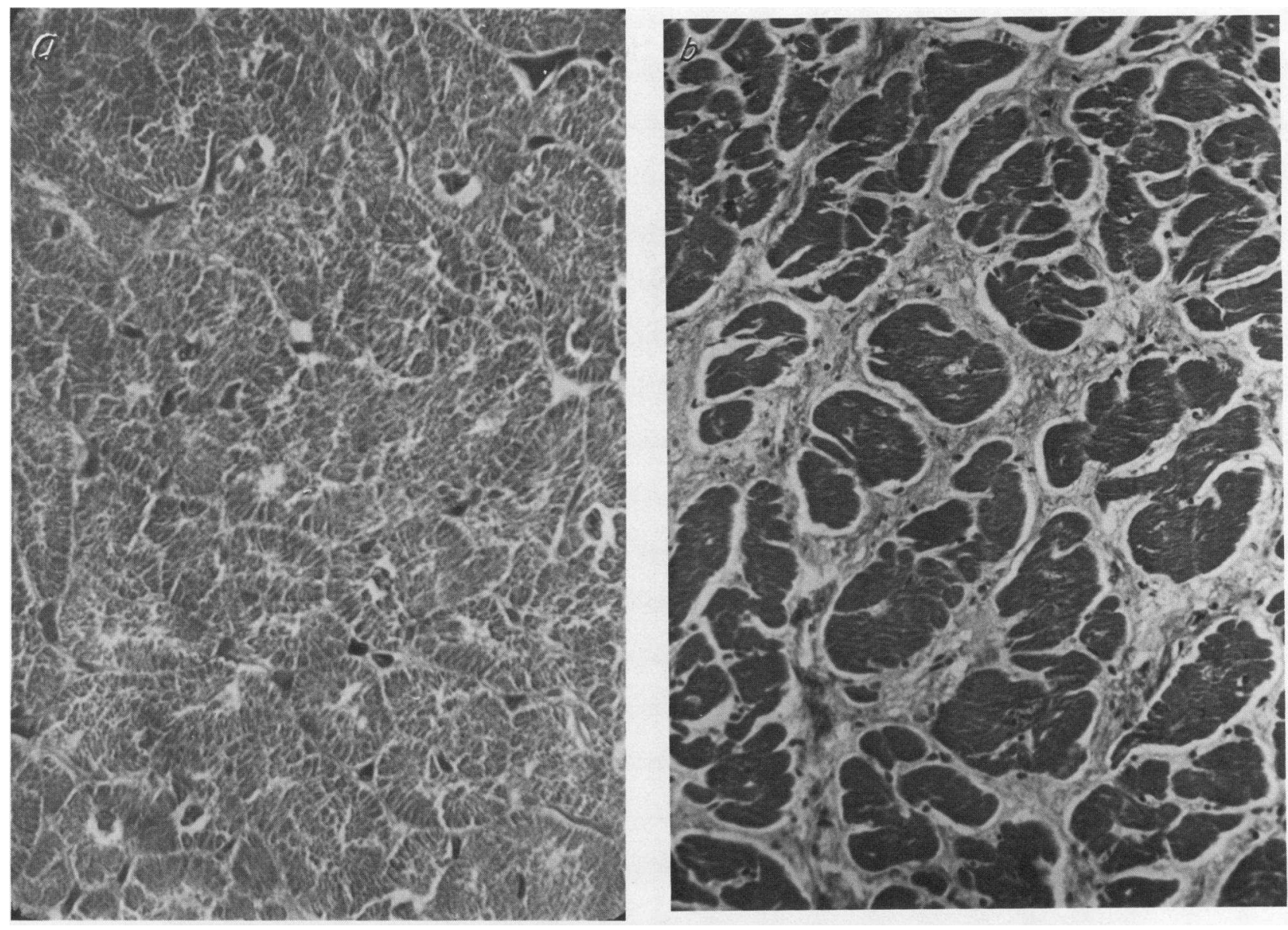

FIGURE 3 (a) This trichrome stain from a sample of left ventricle in the control group illustrates closely packed muscle fibers with minimal staining $(\times 210)$. $(b)$ This trichrome stain for collagen in a cross section of diabetic myocardium illustrates deposits that are diffusely scattered throughout the interstitium $(\times 240)$. The tissue was graded as $3+$.

normal, diminished end-diastolic compliance was also observed, without hypertrophy or altered indices of contractility (4).

It is noteworthy that the progression from the functional cardiac abnormality of familial diabetes exhibited in group A-1 to a state of clinical decompensation does not require concomitant complications such as hypertension, marked obesity, or significant coronary atherosclerosis. While a mechanism is not clear, the amount and distribution of glycoprotein and collagen in the interstitium may constitute a major determinant of progression. Nondiabetic patients who have cardiomyopathy without hypertension or myocardial infarction may exhibit similar hemodynamic abnormalities as seen in diabetes. Thus, the response to after- load increments manifested as an abnormal rise of ventricular filling pressure without a stroke volume increase has also been observed in the preclinical phase of alcoholic cardiomyopathy (6), in which the interstitium is also altered (59). After the onset of decompensation the diabetic myocardium presumably exhibits properties similar to other etiologic types. Altered interstitium may be the predominant lesion in the incipient stages of amyloid heart disease where end-diastolic pressure rather than volume elevations are characteristic (58). A similar, although less pronounced, pressure-volume abnormality may exist in diabetes. In addition, the extracellular pathologic process may limit the rate of calcium movement into the cardiac cell and with progression may result in iso-

Figure 2 (a) A representative sample of left ventricle from the control group stained with PAS $(\times 240)$. (b) A representative myocardial specimen in cross section from a diabetic patient shows the presence of PAS-positive material which appeared to be most prominent at the periphery of cardiac muscle fibers $(\times 210)$. This was read as $3+$. 


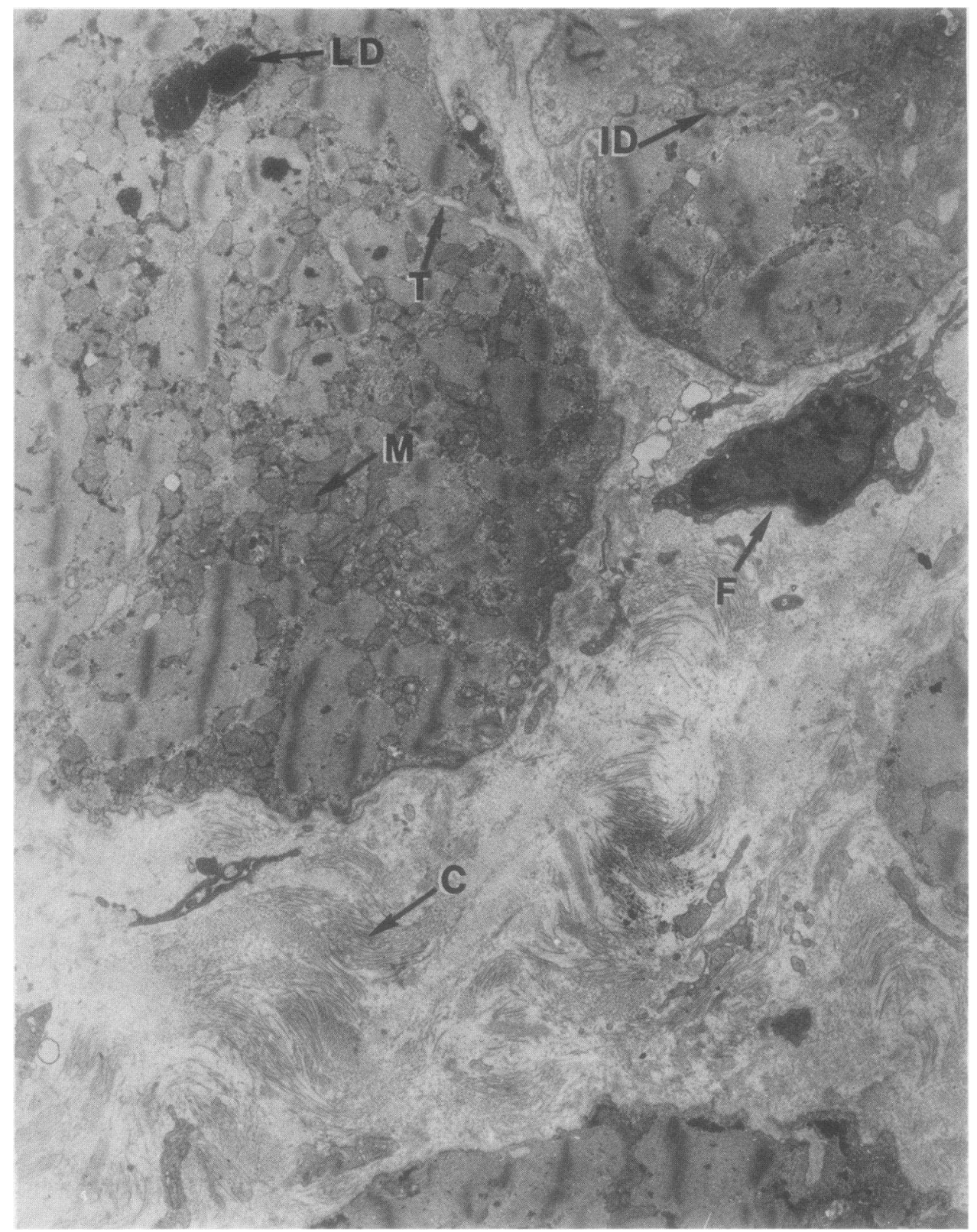

FIGURE 4 The biopsy specimen $(\times 16,000)$ from a diabetic patient undergoing cardiac surgery illustrates the borders of four cardiac muscle cells with substantial accumulation of fibers in the interstitium, having the characteristic periodicity of collagen $(C)$. 'The fibroblast $(F)$ exhibited margination of chromatin in the nucleus and a relative abundance of rought endoplasmic reticulum. Cardiac muscle cells had an increase in number and pleomorphism of mitochondria (M) and occasional lipofuscin deposits (LD). Transverse tubules (T) were prominent, and the myofibrils, intercalated disk (ID) and sarcoplasmic reticulum were relatively normal. Focal glycogen increments are also present.

lation of myofibers or their replacement (60), with consequent effects on cardiac function.

In a chronic animal model of insulinopenic diabetes (4) as well as in a small series of human diabetics (61), histochemical evidence of glycoprotein accumula- tion in myocardial interstitium has been previously observed. In the former, the PAS-positive material generally assumed a brownish-red amorphous appearance within the myocardial interstitium (4), in contrast to collagen which stains pale pink (62). This 
apparent glycoprotein accumulation also presented as linear streaks related to the surface of cardiac fibers. In this freshly obtained muscle, the PAS stain was associated with a grayish cell background, but in human postmortem hearts, the background was pink despite close attention to staining and photographic techniques. An artifactual basis may exist due to the postmortem interval before myocardial sampling.

In the diabetic patients of this study, PAS-positive material was usually present in increased amounts compared to nondiabetic controls. Less amorphous than in the canine diabetic, the process assumed a reddish, more fibrous form, perhaps dependent on duration and intensity of the disease. This was most pronounced in close apposition to the cardiac muscle fiber and may be related to the amorphous material observed in the tubular system and along the cell surface by electron microscopy (Fig. 4). The truly interstitial, more filamentous, PAS-positive material may represent collagen staining, either due to associated carbohydrate complexes or to additional glycoprotein associated with the collagen fibers. A diffuse distribution of collagen was observed throughout the interstitium on trichrome stains (Fig. 3).

Although traditionally associated with capillary basement membrane, glycoprotein staining material has previously been observed in the interstitial tissue of the glomerular mesangium (63) as well as myocardium (61). Although frequently homogenous in appearance, fine tortuous PAS-positive filamentous deposits have been observed in the interstitium of many organs (61). These may appear finely fibrillar on electron microscopy when associated with fibrous structures.

Although the pathologic observations did not include an examination of the question of specificity for diabetic myocardium, these findings differ not only from the classical infiltrative myopathies but also that associated with alcoholism, where Alcian blue material has been observed with or without collagen increments in man (59), as well as in the experimental animal (64). However, differentiation from other causes of cardiomyopathy is presently uncertain when morphologic data from other tissues is unavailable.

On the basis of observations in the animal model, glycoprotein increments appear to occur relatively early in the course of diabetes associated with diminished diastolic compliance without an evident increase of interstitial collagen (4). Although no morphologic observations were made in the patients studied hemodynamically, the functional observations in group A-1 are consistent with accumulation of PAS-positive material. Whether collagen increments are present at this stage and the quantitative relations to glycoprotein as cardiac dysfunction progresses is not known. The presence of collagen to varying extent in the human postmortem and biopsy specimens pre-

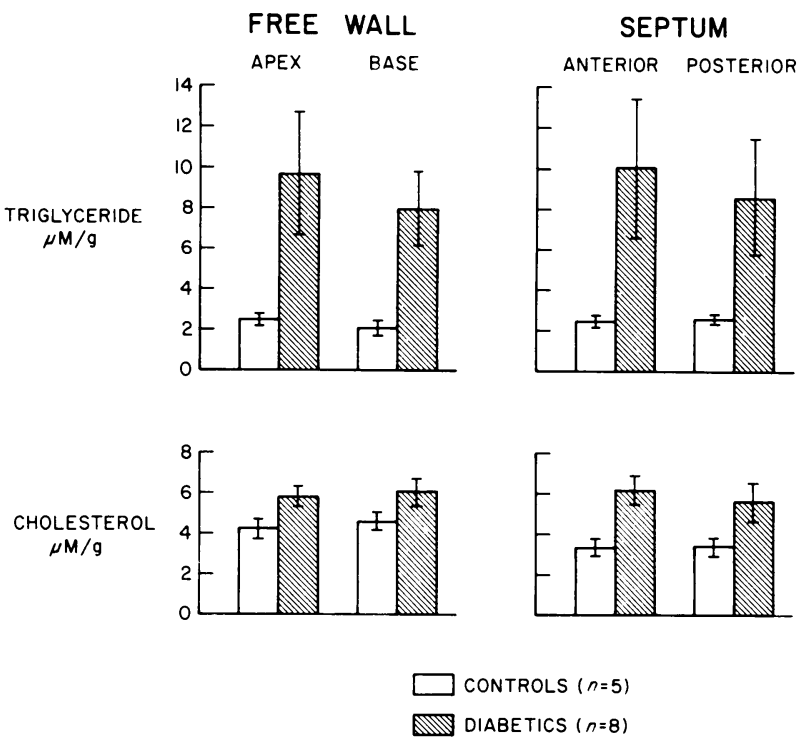

Figure 5 Myocardial concentrations of triglyceride and cholesterol were significantly increased at multiple sampling sites in diabetic patients.

sumably is, amongst othes factors, a time-dependent process. Morphologic evidence of active fibroblasts by electron microscopy may permit the inference of enhanced collagen synthesis, but diminished degradation rates could be contributory. The findings of collagen increments in diabetic glomeruli suggest a multiorgan metabolic abnormality (65).

Lipid analysis of postmortem myocardium was undertaken with some reservation in view of the time between death and tissuc sampling. However, the major lipid classes do not appear to change substantially in this time span, as judged by comparison of subjects succumbing to a variety of causes in whom concentrations were not significantly different from in vivo biopsy specimens (66). The observed increments of myocardial triglyceride and cholesterol concentrations observed in the diabetic patients compared to controls of the same age range dying of noncardiac causes, is in accord with prior reports $(67,4)$. Inasmuch as lipid accumulation was observed in samples taken from multiple sites in the heart (Fig. 4), the diffuse abnormality of lipid metabolism is consistent with a cardiomyopathic process.

The available serum cholesterol and triglyceride levels of these subjects were within the normal range in the majority, in agreement with three prior studies indicating that elevated serum lipids are observed in approximately one-third of the diabetic population (6870). However, increments of plasma free fatty acids observed in the animal model (4) as well as in human diabetics (71), may facilitate the process of triglyceride accumulation in myocardium. 


\section{ACKNOWLEDGMENTS}

The authors gratefully acknowledge the technical assistance of Remy Torres, Louisa Titus, and Bess Jenkins, the secretarial assistance of Anne Binetti and Audrey Brown, and the nursing assistance of Linda Jordan, R.N., and Marguerite Brown, L.P.N.

This investigation was supported in part by research grant HL 09914 and postgraduate training grant HL 05510 from the National Heart and Lung Institute and by a research grant from the Essex County Heart Association, New Jersey affiliate of the American Heart Association.

\section{REFERENCES}

1. Kessler, I. I. 1971. Mortality experience in diabetic patients. A twenty-six year follow-up study. Am. J. Med. 51: 715-724.

2. Vihert, A. M., V. S. Zhdanov, and E. E. Matova. 1969. Atherosclerosis of the aorta and coronary vessels of the heart in cases of various disease. J. Atheroscler. Res. 9: 179-192.

3. Ledet, T. 1968. Histological and histochemical changes in the coronary arteries of old diabetic patients. Diabetologia. 4: 268-272.

4. Regan, T. J., P. O. Ettinger, M. I. Khan, M. U. Jesrani, M. M. Lyons, H. A. Oldewurtel, and M. Weber. 1974. Altered myocardial function and metabolism in chronic diabetes mellitus without ischemia in dogs. Circ. Res. 35: 222-237.

5. Ahmed, S. S., T. J. Regan, G. A. Jaferi, and R. M. Narang. 1975. Preclinical reduction of left ventricular function in diabetes mellitus. Am. Heart J. 89: 153-158.

6. Regan, T. J., G. E. Levinson, H. A. Oldewurtel, M. J. Frank, A. B. Weisse, and C. B. Moschos. 1969. Ventricular function in noncardiacs with alcoholic fatty liver. The role of ethanol in the production of cardiomyopathy. J. Clin. Invest. 48: 397-407.

7. Spodick, D. H., V. M. Pigott, and R. Chirife. 1972. Preclinical cardiac malfunction in chronic alcoholism. Comparison with matched normal controls and with alcoholic cardiomyopathy. N. Engl. J. Med. 287: 677-680.

8. Ettinger, P. O., H. A. Oldewurtel, B. Dzindzio, V. Sethi, and T. J. Regan. 1971. Glucose intolerance in nonischemic cardiac disease. Role of cardiac output and adrenergic function. Circulation 43: 809-823.

9. Fredrickson, D. S., R. I. Levy, and R. S. Lees. 1967. Fat transport in lipoproteins. An integrated approach to mechanisms and disorders. N. Engl. J. Med. 276: $148-156$.

10. Kjeldsen, H., A. P. Hansen, and K. Lundbaek. 1975. Twenty-four-hour serum growth hormone levels in maturity-onset diabetics. Diabetes. 24: 977-982.

11. Dyer, A. R., J. Stamler, D. M. Berkson, and H. A. Lindberg. 1975. Relationship of relative weight and body mass index to 14-year mortality in the Chicago Peoples Gas Company Study, J. Chronic. Dis. 28: 109-123.

12. Falsetti, H. L., R. E. Mates, D. G. Greene, and I. L. Bunnell. 1971. $\mathrm{V}_{\max }$ as an index of contractile state in man. Circulation. 43: 467-479.

13. Levinson, G. E., M. J. Frank, M. Nadimi, and M. Braunstein. 1967. Studies of cardiopulmonary blood volume: Measurement of left ventricular volume by dye dilution. Circulation. 35: 1038-1048.

14. Maseri, A., and Y. Enson. 1968. Mixing in the right ventricle and pulmonary artery in man: evaluation of ventricular volume measurements from indicator washout curves. J. Clin. Invest. 47: 848-859.
15. Newman, E. V., M. Merrell, A. Genecin, C. Monge, W. R. Milnor, and W. P. McKeever. 1951. The dye dilution method for describing the central circulation. An analysis of factors shaping the time-concentration curves. Circulation. 4: 723-746.

16. Keroes, J., and E. Rapaport. 1972. Ventricular volume measurement in the awake dog using implanted thermistor beads. J. Appl. Physiol. 32: 404-408.

17. Brown, A. K., E. J. Epstein, N. Coulshed, J. M. Clarke, and N. G. Doukas. 1969. Haemodynamic changes after angiocardiography. Br. Heart J. 31: 233-245.

18. Hugenholtz, P. G., H. R. Wagner, and H. Sandler. 1968. In vivo determination of left ventricular volume: Comparison of the fiberoptic-indicator dilution and the angiocardiographic methods. Circulation. 37: 489-508.

19. Mullins, C. B., S. J. Leshin, D. S. Mierzwiak, H. D. Alsobrook, and J. H. Mitchell. 1972. Changes in left ventricular function produced by the injection of contrast media. Am. Heart J. 83: 373-381.

20. Swan, H., V. Ganz, J. C. Wallace, and K. Tamura. 1968. Left ventricular end-diastolic volume (EDV) by angiographic and thermal methods in a single diastole. Circulation. 38: VI-193.

21. Frank, M. J., P. E. Cundy, Jr., T. L. Crews, and W. J. Lewis, III. 1971. Comparison of left ventricular volumes by single-plane cineangiography and by indicator dilution. J. Lab. Clin. Med. 77: 580-593.

22. Ross, J., Jr., and E. Braunwald. 1964. Study of left ventricular function in man by increasing resistance of ventricular ejection with angiotensin. Circulation. 29: 739-749.

23. Sones, F. J., Jr., and E. K. Shirley. 1962. Cine coronary arteriography. Mod. Concepts Cardiovas. Dis. 31: 735738.

24. Bruschke, A. V. G., W. L. Proudift, and F. M. Sones, Jr. 1973. Clinical course of patients with normal and slightly or moderately abnormal coronary arteriograms. A follow-up study on 500 patients. Circulation. 47: 936-945.

25. Green, D., G. R. Carlisle, C. Grant, and I. L. Bunnell. 1967. Estimation of left ventricular volume by one-plane cineangiography. Circulation. 35: 61-69.

26. Kennedy, J. W., D. D. Reichenbach, W. A. Baxley, and H. T. Doge. 1967. Left ventricular mass: Comparison of angiocardiographic measurements with autopsy weight. Am. J. Cardiol. 19: 221-223.

27. Herman, M. V., R. A. Heinle, M. D. Klein, and R. Gorlin. 1967. Localized disorders in myocardial contraction. Asynergy and its role in congestive heart failure. N. Engl. J. Med. 277: 222-232.

28. Lowry, O. H., J. V. Passonneau, F. X. Hasselberger, and D. W. Schulz. 1964. Effect of ischemia on known substrates and cofactors of the glycolytic pathway in brain. J. Biol. Chem. 239: 18-30.

29. Greengard, P. 1956. Determination of intermediary metabolites by enzymic fluorimetry. Nature (Lond.). 178: $632-634$.

30. Luna, L. G. 1968. Manual of Histologic Staining Methods of the Armed Forces Institute of Pathology. McGrawHill Book Company, New York. 3rd edition. 258 pp.

31. Pearse, A. G. E. 1968. Histochemistry: Theoretical and Applied. Little, Brown \& Co. Inc., Boston. 3rd edition. 1: 660,684 .

32. Hays, W. L., and R. L. Winkle. 1970. Statistics: Probability, Inference, and Decision. Holt, Rinehart \& Winston, Inc., New York, I, II.

33. Gault, J. H., J. Ross, Jr., and E. Braunwald. 1968. Contractile state of the left ventricle in man. Instantaneous 
tension-velocity-length relations in patients with and without disease of the left ventricular myocardium. Circ. Res. 22: 451-463.

34. Falsetti, H. L., R. E. Mates, C. Grant, D. G. Greene, and I. L. Bunnell. 1970. Left ventricular wall stress calculated from one-plane cineangiography. Circ. Res. 26: 71-83.

35. Kessler, G., and H. Lederer. 1965. Fluorometric measurement of triglycerides. In Automation in Analytical Chemistry. Technicon Symposia, Mediad, Inc., White Plains, N.Y. 341-344.

36. Bartlett, G. 1959. Phosphorous assay in column chromatography. J. Biol. Chem. 234: 466-468.

37. Levine, J. B., and B. Zak. 1964. Automated determination of serum total cholesterol. Clin. Chim. Acta. 10: 381-384.

38. Kannel, W. B., M. Hjortland, and W. P. Castelli. 1974. Role of diabetes in congestive heart failure: The Framingham Study. Am. J. Cardiol. 34: 29-34.

39. Blumenthal, H. T., M. Alex, and S. Goldenberg. 1960. A study of lesions of the intramural coronary artery branches in diabetes mellitus. Arch. Pathol. 70: 13-28.

40. Rubler, S., J. Dlugash, Y. Z. Yuceoglu, T. Kumral, A. W. Branwood, and A. Grishman. 1972. A new type of cardiomyopathy associated with diabetic glomerulosclerosis. Am. J. Cardiol. 30: 595-602.

41. Hamby, R. I., S. Zoneraich, and L. Sherman. 1974. Diabetic cardiomyopathy. J.A.M.A. (J. Am. Med. Assoc.) 229: 1749-1954.

42. Schwartz, C. J., and J. R. A. Mitchell. 1962. The relation between myocardial lesions and coronary artery disease. Br. Heart J. 24: 761-786.

43. Buja, L. M., N. B. Khoi, and W. C. Roberts. 1970. Clinical significant cardiac amyloidosis. Am. J. Cardiol. 26: 394-405.

44. Farrer-Brown, G., M. H. Tarbit, K. Somers, and M. S. R. Hutt. 1972. Microvascular study of hearts with endomyocardial fibrosis. Br. Heart J. 34: 1250-1262.

45. Andrade, Z. A., and A. R. L. Teixeira. 1973. Changes in the coronary vasculature in endomyocardial fibrosis and their possible significance. Am. Heart J. 86: 152-158.

46. Roberts, W. C. 1972. Coronary arteries in fatal acute myocardial infarction. Circulation. 45: 215-230.

47. Perper, J. A., L. H. Kuller, and M. Cooper. 1975. Arteriosclerosis of coronary arteries in sudden, unexpected deaths. Circulation. 52(Suppl. III): III-27-III-33.

48. Parker, J. O., M. A. Chiong, R. O. West, and R. B. Case. 1969. Sequential alterations in myocardial lactate metabolism, S-T segments, and left ventricular function during angina induced by atrial pacing. Circulation. 40: 113-131.

49. Kemp, H. G., Jr., P. S. Vokonas, P. F. Cohn, and R. Gorlin. 1973. The anginal syndrome associated with normal coronary arteriograms. Am. J. Med. 54: 735-742.

50. Dwyer, E. D., Jr. 1970. Left ventricular pressure-volume alterations and regional disorders of contraction during myocardial ischemia induced by atrial pacing. Circulation. 42: 1111-1122.

51. McCans, J. L., and J. O. Parker. 1973. Left ventricular pressure-volume relationships during myocardial ischemia in man. Circulation. 48: 775-785.

52. Bemiller, C. R., C. J. Pepine, and A. K. Rogers. 1973. Long-term observations in patients with angina and normal coronary arteriograms. Circulation. 47: 36-43.

53. Taylor, H. L., A. Henschel, J. Brozek, and A. Keys. 1949.
Effects of bed rest on cardiovascular function and work performance. J. Appl. Physiol. 2: 223-239.

54. Saltin, B., G. Bloomquist, J. H. Mitchell, R. L. Johnson, K. Wildenthal, and C. B. Chapman. 1968. Response to exercise after bed rest and after training. Circulation. 38(Suppl. VII): VII-1.

55. Melada, G. A., R. H. Goldman, J. A. Luetscher, and P. G. Zager. 1975. Hemodynamics, renal function, plasma renin, and aldosterone in man after 5 to 14 days of bedrest. Avia. Space Environ. Med. 46: 1049-1055.

56. Grossman, W., L. P. McLaurin, and M. A. Stefadouros. 1974. Left ventricular stiffness associated with chronic pressure and volume overloads in man. Circ. Res. 35: 793-800.

57. Brady, A. J. 1968. Active state in cardiac muscle. Physiol. Rev. 48: 570-600.

58. Chew, C., G. M. Ziady, M. J. Raphael, and C. M. Oakley. 1975. The functional defect in amyloid heart disease. The "stiff heart" syndrome. Am. J. Cardiol. 36: 438444.

59. Regan, T. J., C. F. Wu, A. B. Weisse, C. B. Moschos, B. Haider, S. S. Ahmed, and M. M. Lyons. 1975. Acute myocardial infarction in toxic cardiomyopathy without coronary obstruction. Circulation. 51: 453-461.

60. Maron, B. J., V. J. Ferrans, and W. C. Roberts. 1975. Myocardial ultrastructure in patients with chronic aortic valve disease. Am. J. Cardiol. 35: 725-739.

61. Sohar, E., M. Ravid, Y. Ben-Shaul, T. Reshef, and J. Gafni. 1970. Diabetic fibrillosis. A report of three cases. Am. J. Med. 49: 64-69.

62. Pearse, A. G. E. 1968. Histochemistry. Theoretical and Applied. Little, Brown \& Co. Inc., Boston. 3rd edition. 1: 214.

63. Heptinstall, R. H. 1974. Diabetes mellitus and gout. In Pathology of the Kidney. Little, Brown \& Co., Inc., Boston. 2nd edition. 2: 934.

64. Regan, T. J., M. I. Khan, P. O. Ettinger, B. Haider, M. M. Lyons, and H. A. Oldewurtel. 1974. Myocardial function and lipid metabolism in the chronic alcoholic animal. J. Clin. Invest. 54: 740-752.

65. Klein, L., D. L. Butcher, O. Sudilovsky, R. Kikkawa, and M. Miller. 1975. Quantification of collagen in renal glomeruli isolated from human nondiabetic and diabetic kidneys. Diabetes. 24: 1057-1065.

66. Fletcher, R. F. 1972. Lipids of human myocardium. Lipids. 7: 728-732.

67. Alvaikko, M., R. Elfving, J. Hirvonen, and J. Jarvi. 1973. Triglycerides, cholesterol, and phospholipids in normal heart papillary muscle and in patients suffering from diabetes, cholelithiasis, hypertension, and coronary atheroma. J. Clin. Pathol. (Lond.). 26: 285-293.

68. Wilson, D. E., P. H. Schreibman, V. C. Day, and R. A. Arky. 1970. Hyperlipidemia in an adult diabetic population. J. Chronic. Dis. 23: 501-506.

69. Garcia, M., P. McNamara, T. Gordon, and W. B. Kannel. 1973. Cardiovascular complications in diabetics. Adv. Metab. Disord. 2:(Suppl. 2): 293-499.

70. Perrett, A. D., A. S. Rows, M. Shahmanesh, S. P. Allison, and M. Hartog. 1974. Blood lipids in treated diabetics. Diabetologia. 10: 115-118.

71. Camerini-Davalos, R. A., W. Opperman, C. Velasco, and H. S. Cole. 1973. Abnormalities at the stage of chemical asymptomatic diabetes. Metab. Clin. Exp. 22: 219-228. 